\title{
Uçak Bakım Teknisyenleri için DEMATEL Yöntemi ile Fiziksel İş Yükü Faktörlerinin Değerlendirilmesi
}

\author{
Yaşar Öztürk ${ }^{1}$, Ebru Yazgan ${ }^{2 *}$ ve Elif Kılıç Delice ${ }^{3}$ \\ ${ }^{1}$ Eskişehir Teknik Üniversitesi, Lisansüstü Eğitim Enstitüsü, Uçak Gövde ve Motor Bakımı Bölümü, Eskişehir, Türkiye (ORCID ID 0000-0002-9023-4972), \\ yasar_ozturk@eskisehir.edu.tr \\ 2*Eskişehir Teknik Üniversitesi, Havacılık ve Uzay Bilimleri Fakültesi, Uçak Gövde ve Motor Bakımı Bölümü, Eskişehir, Türkiye (ORCID ID 0000-0002-6545-8536), \\ eyazgan@eskisehir.edu.tr \\ ${ }^{3}$ Atatürk Üniversitesi, Mühendislik Fakültesi, Endüstri Mühendisliği Bölümü, Erzurum, Türkiye (ORCID ID 0000-0002-3051-0496), elif.kdelice@atauni.edu.tr
}

(1st International Conference on Applied Engineering and Natural Sciences ICAENS 2021, November 1-3, 2021)

(DOI: 10.31590/ejosat.1010051)

ATIF/REFERENCE: Öztürk, Y., Yazgan, E., Delice, E.K. (2021). Uçak Bakım Teknisyenleri İçin DEMATEL Yöntemi ile Fiziksel İş Yükü Faktörlerinin Değerlendirilmesi. Avrupa Bilim ve Teknoloji Dergisi, (28), 1447-1453.

\section{$\ddot{O} z$}

Uçak bakım teknisyenleri (UBT), ağır ve tekrarlı bir şekilde fiziksel yüklere maruz kalmakta ve bu nedenle UBT'lerin iş yükleri artmaktadır. Uçuşun emniyetli bir şekilde yapılması için UBT'lerin fiziksel iş yüklerinin incelenerek gerekli olduğu noktalarda azaltılması son derece önemlidir. Toplam iş yükü değerlendirmesi fiziksel iş yükü faktörlerine bağlı olarak ortaya çıkan bir Çok Kriterli Karar Verme (ÇKKV) problemi olarak ele alınabilir. Bu çalışma kapsamında ise UBT'lerin toplam iş yükü etkenleri içerisinde yer alan fiziksel iş yükü faktörlerinin önceliklendirilmesini hesaplayabilmek için ÇKKV yöntemlerinden biri olan DEMATEL (Decision Making Trial and Evaluation Laboratory) yöntemi kullanılmıştır. Fiziksel iş yükü faktörleri olarak çalışma duruşlarını etkileyen vücut kısımları bel, boyun, omuzlar, sırt, üst kol, ön kol, dirsekler, el bilekleri, kalça, alt bacaklar, ayak bilekleri, dizler ve uyluklar dikkate alınmıştır. Bir uçak bakım organizasyonunda çalışan UBT'ler üzerinde yapılan bu çalışmada en önemli ilk dört faktör bel, sırt, kalça ve dirsekler olarak tespit edilmiştir. Çalışmanın sonucunda elde edilen bulgulara göre UBT'lere iş yüklerinin azaltılması için alınması gereken önlemler sunulmuştur.

Anahtar Kelimeler: Uçak Bakım Teknisyeni, İş yükü, DEMATEL, Çok Kriterli Karar Verme.

\section{Evaluation of Physical Workload Factors with DEMATEL Method for Aircraft Maintenance Technicians}

\begin{abstract}
Aircraft maintenance technicians (AMT) are exposed to heavy and repetitive physical loads, and therefore the workloads of AMTs are increasing. In order to make the flight safely, it is extremely important to reduce the physical workloads of AMTs by examining them where necessary. Total workload assessment can be considered as a Multi-Criteria Decision Making (MCDM) problem that arises depending on physical workload factors. Within the scope of this study, the DEMATEL (Decision-Making Trial and Evaluation Laboratory) method, which is one of the MCDM methods, was used to calculate the prioritization of physical workload factors included in the total workload factors of AMTs. Body parts that affect working postures, waist, neck, shoulders, back, upper arms, forearms, elbows, wrists, hips, lower legs, ankles, knees and thighs were considered as physical workload factors. In this study conducted on AMTs working in an aircraft maintenance organization, the first four most important factors were identified as waist, back, hips and elbows. According to the findings obtained as a result of the study, the measures to be taken to reduce the workloads were presented to the AMTs.
\end{abstract}

Keywords: Aircraft Maintenance Technician, Workload, DEMATEL, Multi-Criteria Decision Making. 


\section{Giriş}

UBT'ler uçak üzerinde planlı veya plansız çeşitli bakım ve onarımlar yapan, uçakların uçuşa elverişliliğinin kontrolünü yapıp onaylayan kalifiye çalışanlardır. Amerika Birleşik Devletleri'nde tarifeli hava taşımacılığı sektöründe yaklaşık 5,5 milyon kişinin istihdam edildiği, bunlardan 35,820'sinin ise bakım ve onarım endüstrisinde çalıştığ belirtilmiştir [1]. Türkiye'de ise 2019 y1lı itibariyle 4547 lisanslı teknisyen görev yapmaktadir [2].

UBT'ler bakım hangarlarında veya pist üzerinde uçakların modifikasyon, arıza giderme, parça değişimi gibi faaliyetlerini yürütürken ağır yük kaldırma, uygun olmayan pozisyonlarda çalışma gibi birtakım fiziksel yüklere maruz kalmaktadır. Bu fiziksel yükler teknisyenlerde kas iskelet sistemi rahatsızlıklarına neden olabilmektedir. Teknisyenler zaman baskısı, anlık plansız bakımlar gibi zihinsel zorlanmalara ve ayrıca çalıştıkları havaalanı veya hangar ortamı gereğince sicaklık, gürültü, aydınlatma gibi çevresel zorlanmalara maruz kalmakta bu da çalışanların iş yüklerine etki etmektedir.

$\mathrm{Bu}$ çalışmada ise UBT'lerin iş sırasında maruz kaldıkları iş yükünün birbiriyle ilişkili birden fazla faktöre bağlı olması nedeniyle ÇKKV yöntemlerinden biri olan DEMATEL yöntemi kullanılarak en önemli iş yükü faktörleri belirlenmiş ve bu faktörlere bağlı olarak iş yüklerinin azaltılması için alınması gereken önlemler açıklanmıştır.

DEMATEL metodu, ilk olarak 1972-1976 yıllarında Cenevre Araştırma Merkezi (Battelle Memorial Institute)'nde karmaşık nedensel ilişkilerin yapısını gözler önüne sermek için kullanılmıştır [3-4]. DEMATEL metodu değerlendirilecek alternatifler arasındaki nedenselliğin çözülmesi ve kriterlerin önemlerinin belirlenmesi açısından en verimli metotlardan biri olarak görülmektedir [5]. DEMATEL metodunda eldeki kriterler neden ve sonuç olmak üzere iki gruba ayrılır. Neden grubunda bulunan kriterlerin diğer kriterler üstündeki etkisinin daha fazla olduğu ve bu yüzden öncelikli olarak değerlendirilmesi gereken kritik grubu olduğu düşünülmektedir. Sonuç grubunda bulunan kriterler ise diğer kriterler tarafından daha fazla etkilendiğinden önceliği düşük olarak ele alınan kriter grubudur [6]. Literatür taraması yapıldığında DEMATEL'in performans analiz çalışmaları [7], hastanelerdeki hizmet kalitesine etki eden kritik faktörleri belirleme [8], kara taşımacılığı yapan bir işletmenin kamyon seçimi [9] gibi birçok farklı alanda tercih edilen bir yöntem olduğu görülmektedir.

Literatür taraması sonucunda UBT'lerin iş yükü faktörlerini özellikle ÇKKV yöntemleri kapsamında inceleyen bir çalışma olmadığı görülmüştür. Bu çalışmada fiziksel iş yükü faktörleri incelenmiştir. Fiziksel iş yükü Cornell Musculoskeletal Discomfort Questionnaire (CMDQ) ve Nordic Musculoskeletal Questionnaire (NQM)'de yer alan vücudun bel, boyun gibi 13 farklı bölgesi dikkate alınarak UBT'lerin iş yüklerinin değerlendirilmesinde kullanılmıştır.

Çalışmanın ikinci bölümünde; fiziksel iş yükü hakkında bilgi verilmiştir. Üçüncü bölümde DEMATEL yönteminin adımları ve UBT'ler için yapılan uygulamadan bahsedilmiştir. Son bölümde ise sonuç ve öneriler verilmiştir.
Kas-iskelet sistemi (KİS) rahatsızlıkları Uluslararası İş Sağlığı ve Güvenliği Komisyonu'nun da tanımladığı gibi kasiskelet sisteminde oluşan ve işten kaynaklanan rahatsılıklar veya hastalıklardır. "İşten kaynaklanan” terimi Dünya Sağlık Örgütü tarafından iş performansı ve iş çevresi gibi iki faktörün etkisiyle başlayan çok etkenli bir hastalığın bilimsel nedenini tanımlamak için kullanılmaktadır. KİS rahatsılıkları özellikle eğilme, doğrulma, tutma, kavrama, bükme ve uzanma gibi basit vücut hareketlerinden kaynaklı meydana gelmektedir. Bunlar günlük yaşamda sağlığa zararı dokunan hareketler değildirler. $\mathrm{Bu}$ hareketleri zararlı hale getiren, çalışma esnasındaki tekrarlar, kuvvet uygulama gereksinimi ve hızl hareketlerdir. KİS rahatsızlıkları anında gelişen değil artan derecelerle yavaş gelişen travmalardir [10].

NMQ ve CMDQ çalışma duruşlarına ve çalışanların fiziksel özelliklerine bağlı olarak fiziksel iş yükü etkilerini ortaya çıkarmak için kullanılan iki anket türüdür. NMQ iki bölümden meydana gelmektedir. İlk bölümde kişilerin yaşı, boyu, ağırlıkları, ne zamandır devam etmekte olduğu işte çalıştığ ve günde kaç saat çalıştığı gibi sorular yer almaktadır. İkinci bölümde ise vücudun belli bölümlere ayrıldığ 9 belirti (semptom) bölgesindeki (boyun, omuzlar, sırt, bel, dirsekler, el bilekleri-eller, ayak bilekleri-ayaklar, uyluklar-kalçalar, dizler) son 12 ayda ve son 7 günde meydana gelen rahatsızlıklar araştırılmaktadır [11]. CMDQ anketinin uygulanma amacı ise çalışanların cinsiyet, mesleği icra ediş şekli ve vücut postürü gibi faktörleri de değerlendirmeye katılarak vücutlarında meydana gelen ağrıların sıklığı, şiddeti ve aynı zamanda iş performanslarına etkilerini hesaplamaktır. Uygulama yapılırken çalışanların son 1 haftada yaşamış oldukları ağrı, sızı vb. rahatsızlıklar dayanak olarak alınır. Rahatsızlıkların sıklığı ve şiddetleriyle ilgili birtakım sorular yöneltilir. Vücudun boyun, omuz (sol-sağ), sırt, üst kol (sol-sağ), bel, ön kol (sol-sağ), el bileği (sol-sağ), kalça, üst bacak (sol-sağ), diz (sol-sağ) ve alt bacak (sol-sağ) olmak üzere toplamda 18 farklı bölgesi için anket soruları yöneltilir ve geri dönüşler alınarak risk puanlaması hesaplanır [12].

\section{Method}

Çalışmada faktör ağırlıklarının belirlenmesi için DEMATEL yöntemi kullanılmıştır. $\mathrm{Bu}$ bölümde önce DEMATEL yönteminden ve yöntemin adımları açıklanmıştır. Daha sonra hat bakımda çalışan UBT'lerin maruz kaldıkları fiziksel iş yükü faktörlerinin ağırlıklandırılmasına ilişkin yöntemin uygulama çalışması sunulmuştur.

\subsection{DEMATEL Yöntemi}

DEMATEL, karmaşık faktörler arasındaki nedensel ilişkileri içeren yapısal bir modeli oluşturmak ve analiz etmek için kapsamlı bir yöntemdir [13]. Görselleştirmelerle problemlerin çözülmesi ve analiz edilmesini sağlayan, grafik teorisi temelli bir yöntemdir [14]. AHP (Analytical Hierarchical Process) yönteminde kriterler birbirleriyle ilişkileri açısından bağımsız bir değerlendirmeye alınmaktadır. Ancak DEMATEL'in kriterler arasında bulunan ilişkiyi ortaya çıkarmaya çalışan bir yöntem olması onu AHP'den ayıran önemli bir özelliktir [15].

\subsection{DEMATEL Yöntem Adımları}

Bu bölümde DEMATEL yönteminin adımları açıklanmıştır.

\section{Fiziksel İş Yükü}

Adım 1: Direkt İlişki Matrisini Oluşturma 
Öncelikle kriterler arasındaki ilişkiler Tablo 1' deki gibi 0-4 puan arasında puanlanarak kriterlerin birbirlerini ne kadar etkilediği anlaşılır.

Tablo 1. İkili Karşılaştırma Skalası

\begin{tabular}{|l|l|}
\hline Sayısal Değer & Tanım \\
\hline 0 & Etkisiz \\
\hline 1 & Düşük Etki \\
\hline 2 & Orta Etki \\
\hline 3 & Yüksek Etki \\
\hline 4 & Çok Yüksek Etki \\
\hline
\end{tabular}

Devamında bulunan sonuçlara göre $\mathrm{n} \times \mathrm{n}$ tipinde bir matris oluşturulur. Bu matrise "Direkt İlişki Matrisi" denmektedir. Tablo 2' ye bakacak olursak Kriter 1, Kriter 2'yi "Yüksek Etkili”" etkilerken Kriter 3, Kriter 2'yi “Düşük Etkili” etkilemektedir.

Tablo 2. Örnek Karşılaştırma

\begin{tabular}{|l|l|l|l|}
\hline & Kriter 1 & Kriter 2 & Kriter 3 \\
\hline Kriter 1 & 0 & 3 & 2 \\
\hline Kriter 2 & 2 & 0 & 1 \\
\hline Kriter 3 & 4 & 1 & 0 \\
\hline
\end{tabular}

Direkt ilişki matrisinin köşegeninde yer alan değerler 0 olmalıdır. Ayrıca simetrik bir matris değildir [16]. Direkt ilişki matrisinde bulunan tüm $x_{i j}$ elemanlarında kriter i'nin kriter j'ye olan ilişkisi ifade edilir. $\mathrm{p}$ değeri danışılan uzman sayısını yani kaç tane direkt ilişki matrisi oluşturulduğunu belirtir. Oluşturulan tabloya göre aşağıda bulunan Eşitlik (1) kullanılarak ortalama değerler bulunur ve sonuçlara göre ortalama direkt ilişki matrisi oluşturulur. Oluşturulan bu A matrisi karar verici konumda olan uzman grubun ortak kararını gösterir.

$$
\begin{aligned}
& a_{\mathrm{ij}}=\frac{1}{P} \sum x_{\mathrm{ij}} \mathrm{i}, \mathrm{j} \in\{1,2, \ldots \ldots, n\} \\
& \mathrm{A}=\left[\begin{array}{ccc}
0 & \cdots & \mathrm{a}_{1 \mathrm{n}} \\
\vdots & \ddots & \vdots \\
\mathrm{a}_{\mathrm{n} 1} & \cdots & 0
\end{array}\right]
\end{aligned}
$$

\section{Adım 2: Normalleştirilmiş Direkt İlişki Matrisinin Oluşturulması}

Adım 1'de bulunmuş olan direkt ilişki matrisi A Eşitlik (3)(4) kullanılarak normalleştirilmiş direkt ilişki matrisi (M) elde edilir.

$\mathrm{k}=\min \left(\frac{1}{\max \sum_{j=1}^{n}\left|a_{i j}\right|}, \frac{1}{\max \sum_{j=1}^{n}\left|a_{i j}\right|}\right)$

$\mathrm{M}=\mathrm{k} \times \mathrm{A}$

Direkt ilişki matrisinde olduğu gibi normalleştirilmiş direkt ilişki matrisinde de köşegen değerleri 0 olmalıdır [17]. Kalan değerler 0 ve 1 arasında olmalıdır.

\section{Adım 3: Toplam İlişki Matrisi (T)’nin Oluşturulması}

Normalleştirilmiş ilişki matrisi bulunduktan sonra Eşitlik (5)'nın kullanılmasıyla T matrisi oluşturulur.

$$
\mathrm{T}=\mathrm{M}(\mathrm{I}-\mathrm{M})^{-1}
$$

Eşitlik (6)'da verilen $I, \mathrm{n} \times \mathrm{n}$ boyutlarında olan bir birim matristir.

\section{Adım 4: Gönderici ve Alıcı Gruplarının Belirlenmesi}

Eşitlik (6)-(8) kullanılarak oluşturulan T matrisinde i'nci satır toplamı olan $\mathrm{R}_{\mathrm{i}}$, $\mathrm{i}$ kriterinin diğer kriterlere doğrudan ve dolaylı etkilerinin toplamını verir. $\mathrm{C}_{\mathrm{i}}$ ise $\mathrm{T}$ matrisindeki sütunların toplamını verir ve diğer kriterlerin oluşturduğu etki toplamını ifade eder.

$$
\begin{aligned}
\mathrm{T} & =\left|T_{i, j}\right|_{\mathrm{nxn}}, \mathrm{i}, \mathrm{j} \in\{1,2, \ldots ., n\} \\
\mathrm{R}_{\mathrm{i}} & =\sum_{j=1}^{n} \mathrm{~T}_{\mathrm{i}, \mathrm{j}} \\
\mathrm{C}_{\mathrm{i}} & =\sum_{i=1}^{n} \mathrm{~T}_{\mathrm{i}, \mathrm{j}}
\end{aligned}
$$

$\mathrm{R}_{\mathrm{i}}-\mathrm{C}_{\mathrm{i}}$ 'de pozitif değerlerlere sahip kriterlerin, diğer kriterler üzerinde daha yüksek etkiye sahip olduğunu yani gönderici kriter grubunu; $\mathrm{R}_{\mathrm{i}}-\mathrm{C}_{\mathrm{i}}$ değeri için negatif değere sahip olan kriterler ise diğer kriterlerden daha fazla etkilendiklerini yani alıcı grubunu gösterir. $\mathrm{R}_{\mathrm{i}}+\mathrm{C}_{\mathrm{i}}$ değerleri herhangi bir kriterin diğer kriterler ile arasındaki ilişkisini göstermektedir.

\section{Adım 5: Kriter Ă̆ırlıklarının Belirlenmesi}

Eşitlik (9) ve Eşitlik (10) kullanılarak kriter ağırlıkları belirlenir.

$$
\begin{aligned}
w_{i} & =\sqrt{\left[R_{i}+C_{i}\right]^{2}+\left[R_{i}-C_{i}\right]^{2}} \\
w_{i}^{*} & =\frac{w_{i}}{\sum_{i=1}^{n} w_{i}}
\end{aligned}
$$

Burada $w_{i}^{*}$ i.ninci kriterin nihai ağırlık değeridir.

\subsection{Uygulama}

Uçak bakım teknisyenleri (UBT)'ler hava aracı bakım kuruluşlarında ağırlıklı olarak hat ve üs bakımda çalışırlar. Hat bakımda çalışan teknisyenler zaman baskısı altında hava aracı veya hava aracı parçasının onaylanmış standartlara uygun olarak hangar gerektirmeyen bakım, onarım, parça değiştirme ve arıza giderme işlemlerini yaparlar. Üs bakımda çalışan teknisyenler ise hava aracı üzerinde, hangar ve atölye mekânlarında onaylanmış standartlara göre modifikasyon, onarım, parça değiştirme veya hasar giderme işlemlerini yaparlar. Uçak bakım teknisyenleri, işleri gereği ağır yükler kaldırmakta, bakım ve onarım esnasında ise kas iskelet yaralanmalarına neden olacak yüksek riskli pozisyonlarda çalışmaktadırlar.

İş ortamında yaşanan kas iskelet yaralanmaları uçak bakım teknisyenleri tarafindan sıkılıkla rapor edilen durumlardandır. Örneğin bakım onarım çalışanlarında kas iskelet yaralanmalarının \%35,4'ünü burkulma, incinme, yırtılma; \%9'unu ise kırılmalar oluşturmaktadır [18]. Bu durumdan vücutta en çok etkilenen bölgeler bel, omuzlar, ayaklar, bacaklar, boyun, eller ve kollardır [19]. Yapılan bir araştırmada teknik personelde bel ağrısı görülme sıklığı \%65 olarak ölçülmüştür. Araştırma ve anket sonuçlarına göre bu ağrılara neden olan faktörler arasında fiziksel olarak ağır yüklerle çalışma, eğilme, gövdeyi burkarak çalışma [20] ve özellikle el ile bilek bölgelerinde olmak üzere titreşimli yüklere maruz kalma [20] gibi etkenler vardır. Bu faktörler uçak teknisyenlerindeki fiziksel iş yükünü oluşturmaktadır. Bunların 
yanında teknisyenlerin ofiste geçirdikleri zamanın [22] ve çalışma sürelerinin [20] de kas iskelet yaralanmalarına neden olan faktörlerden olabileceği görülmüştür.

Bu uygulamada DEMATEL yöntemi uygulanarak UBT'lerin fiziksel iş yükleri önceliklendirilmiştir. DEMATEL yöntemi 5 adımda uygulanmıştır.

\section{Adım 1: Direkt İlişki Matrisini Oluşturma}

İlk olarak hat bakım konusunda üç uzman tarafindan Tablo 1 'de verilen skala kullanılarak üç farklı direk ilişki matrisi oluşturulmuş ve daha sonra Eşitlik (1)-(2) kullanılarak ortalama direk ilişki matrisi Tablo 3'de gösterildiği gibi elde edilmiştir.
Adım 2: Normalleştirilmiş Direkt İlişki Matrisinin Oluşturulması

Bu aşamada Tablo 3'de gösterilen ortalama direk ilişki matrisi Eşitlik (3) kullanılarak normalize edilmiş ve Tablo 4'de gösterilen normalleştirilmiş direk ilişki matrisi elde edilmiştir.

\section{Adım 3: Toplam İlişki Matrisi (T)'nin Oluşturulması}

Normalleştirilmiş ilişki matrisi ve Eşitlik (5) kullanılarak toplam ilişki matrisi Tablo 5'de gösterildiği gibi oluşturulmuştur.

Tablo 3. Ortalama Direkt İlişki Matrisi

\begin{tabular}{|c|c|c|c|c|c|c|c|c|c|c|c|c|c|}
\hline $\begin{array}{c}\text { Kriterler } \\
\text { (Faktörler) }\end{array}$ & Boyun & Omuzlar & Dirsekler & $\begin{array}{c}\text { EI } \\
\text { Bilekleri }\end{array}$ & Sirt & Bel & Kalça & Dizler & $\begin{array}{c}\text { Ayak } \\
\text { Bilekleri }\end{array}$ & $\begin{array}{l}\text { Üst } \\
\text { Kol }\end{array}$ & $\begin{array}{l}\text { Ön } \\
\text { Kol }\end{array}$ & Uyluk & $\begin{array}{c}\text { Alt } \\
\text { Bacak }\end{array}$ \\
\hline Boyun & 0.00 & 2.00 & 3.33 & 2.00 & 2.33 & 2.00 & 2.33 & 1.33 & 2.67 & 2.67 & 2.00 & 2.00 & 1.67 \\
\hline Omuzlar & 3.00 & 0.00 & 3.00 & 3.00 & 1.33 & 1.33 & 3.00 & 3.67 & 3.00 & 1.33 & 1.67 & 2.00 & 3.00 \\
\hline Dirsekler & 1.00 & 1.00 & 0.00 & 1.00 & 0.67 & 0.33 & 1.67 & 2.00 & 1.00 & 1.33 & 1.00 & 1.00 & 1.00 \\
\hline EI Bilekleri & 1.33 & 1.33 & 2.67 & 0.00 & 1.00 & 1.33 & 1.33 & 2.00 & 2.00 & 1.00 & 1.00 & 2.00 & 1.67 \\
\hline Kalça & 1.67 & 2.00 & 2.33 & 2.00 & 0.67 & 0.67 & 0.00 & 1.33 & 1.33 & 2.33 & 2.33 & 1.33 & 1.33 \\
\hline Dizler & 3.00 & 1.67 & 3.00 & 2.67 & 0.67 & 1.00 & 3.00 & 0.00 & 3.00 & 3.67 & 3.00 & 2.00 & 2.00 \\
\hline $\begin{array}{c}\text { Ayak } \\
\text { Bilekleri }\end{array}$ & 1.33 & 1.33 & 1.33 & 1.00 & 0.67 & 1.00 & 2.67 & 2.00 & 0.00 & 1.67 & 1.33 & 1.33 & 1.33 \\
\hline Üst Kol & 0.67 & 1.33 & 2.67 & 3.00 & 1.00 & 0.67 & 2.67 & 1.33 & 1.67 & 0.00 & 1.33 & 1.33 & 1.67 \\
\hline Alt Bacak & 1.33 & 1.33 & 2.67 & 1.33 & 1.00 & 0.67 & 1.33 & 1.33 & 2.67 & 1.33 & 1.33 & 1.33 & 0.00 \\
\hline
\end{tabular}

Tablo 4. Normalleştirilmiş Direkt İlişki Matrisi

\begin{tabular}{|c|c|c|c|c|c|c|c|c|c|c|c|c|c|}
\hline $\begin{array}{c}\text { Kriterler } \\
\text { (Faktörler) }\end{array}$ & Boyun & Omuzlar & Dirsekler & $\begin{array}{c}\text { El } \\
\text { Bilekleri }\end{array}$ & Sirt & Bel & Kalça & Dizler & $\begin{array}{c}\text { Ayak } \\
\text { Bilekleri }\end{array}$ & $\begin{array}{l}\text { Üst } \\
\text { Kol }\end{array}$ & $\begin{array}{l}\text { Ön } \\
\text { Kol }\end{array}$ & Uyluk & $\begin{array}{c}\text { Alt } \\
\text { Bacak }\end{array}$ \\
\hline Boyun & 0.00 & 0.04 & 0.07 & 0.04 & 0.05 & 0.04 & 0.05 & 0.03 & 0.06 & 0.06 & 0.04 & 0.04 & 0.04 \\
\hline Omuzlar & 0.06 & 0.00 & 0.06 & 0.06 & 0.03 & 0.03 & 0.06 & 0.08 & 0.06 & 0.03 & 0.04 & 0.04 & 0.06 \\
\hline Dirsekler & 0.02 & 0.02 & 0.00 & 0.02 & 0.01 & 0.01 & 0.04 & 0.04 & 0.02 & 0.03 & 0.02 & 0.02 & 0.02 \\
\hline El Bilekleri & 0.03 & 0.03 & 0.06 & 0.00 & 0.02 & 0.03 & 0.03 & 0.04 & 0.04 & 0.02 & 0.02 & 0.04 & 0.04 \\
\hline Kalça & 0.04 & 0.04 & 0.05 & 0.04 & 0.01 & 0.01 & 0.00 & 0.03 & 0.03 & 0.05 & 0.05 & 0.03 & 0.03 \\
\hline Dizler & 0.06 & 0.04 & 0.06 & 0.06 & 0.01 & 0.02 & 0.06 & 0.00 & 0.06 & 0.08 & 0.06 & 0.04 & 0.04 \\
\hline $\begin{array}{c}\text { Ayak } \\
\text { Bilekleri }\end{array}$ & 0.03 & 0.03 & 0.03 & 0.02 & 0.01 & 0.02 & 0.06 & 0.04 & 0.00 & 0.04 & 0.03 & 0.03 & 0.03 \\
\hline Üst Kol & 0.01 & 0.03 & 0.06 & 0.06 & 0.02 & 0.01 & 0.06 & 0.03 & 0.04 & 0.00 & 0.03 & 0.03 & 0.04 \\
\hline Alt Bacak & 0.03 & 0.03 & 0.06 & 0.03 & 0.02 & 0.01 & 0.03 & 0.03 & 0.06 & 0.03 & 0.03 & 0.03 & 0.00 \\
\hline
\end{tabular}


European Journal of Science and Technology

Tablo 5. Toplam İlişki Matrisi

\begin{tabular}{|c|c|c|c|c|c|c|c|c|c|c|c|c|c|}
\hline $\begin{array}{c}\text { Kriterler } \\
\text { (Faktörler) }\end{array}$ & Boyun & Omuzlar & Dirsekler & $\begin{array}{c}\text { El } \\
\text { Bilekleri }\end{array}$ & Sırt & Bel & Kalça & Dizler & $\begin{array}{c}\text { Ayak } \\
\text { Bilekleri }\end{array}$ & $\begin{array}{c}\text { Üst } \\
\text { Kol }\end{array}$ & $\begin{array}{c}\text { Ön } \\
\text { Kol }\end{array}$ & $\begin{array}{c}\text { Uyluk } \\
\text { Alt } \\
\text { Bacak }\end{array}$ \\
\hline Boyun & 0.04 & 0.08 & 0.12 & 0.09 & 0.07 & 0.06 & 0.10 & 0.07 & 0.10 & 0.10 & 0.08 & 0.08 & 0.08 \\
\hline Omuzlar & 0.10 & 0.04 & 0.12 & 0.11 & 0.05 & 0.05 & 0.12 & 0.12 & 0.11 & 0.08 & 0.08 & 0.08 & 0.10 \\
\hline Dirsekler & 0.04 & 0.04 & 0.03 & 0.04 & 0.02 & 0.02 & 0.06 & 0.06 & 0.04 & 0.05 & 0.04 & 0.04 & 0.04 \\
\hline El Bilekleri & 0.06 & 0.05 & 0.09 & 0.03 & 0.04 & 0.04 & 0.06 & 0.07 & 0.08 & 0.05 & 0.05 & 0.07 & 0.06 \\
\hline Sirt & 0.15 & 0.15 & 0.17 & 0.16 & 0.04 & 0.11 & 0.17 & 0.15 & 0.16 & 0.16 & 0.15 & 0.15 & 0.15 \\
\hline Bel & 0.14 & 0.15 & 0.18 & 0.16 & 0.11 & 0.04 & 0.17 & 0.15 & 0.17 & 0.16 & 0.15 & 0.15 & 0.15 \\
\hline Kalça & 0.06 & 0.07 & 0.09 & 0.07 & 0.03 & 0.03 & 0.04 & 0.06 & 0.06 & 0.08 & 0.07 & 0.05 & 0.06 \\
\hline Dizler & 0.10 & 0.07 & 0.12 & 0.10 & 0.04 & 0.04 & 0.11 & 0.04 & 0.11 & 0.12 & 0.10 & 0.08 & 0.08 \\
\hline $\begin{array}{c}\text { Ayak } \\
\text { Bilekleri }\end{array}$ & 0.05 & 0.05 & 0.06 & 0.05 & 0.03 & 0.04 & 0.09 & 0.07 & 0.03 & 0.06 & 0.05 & 0.05 & 0.05 \\
\hline Üst Kol & 0.04 & 0.05 & 0.09 & 0.09 & 0.04 & 0.03 & 0.09 & 0.06 & 0.07 & 0.03 & 0.05 & 0.05 & 0.06 \\
\hline Ön Kol & 0.05 & 0.06 & 0.06 & 0.07 & 0.03 & 0.03 & 0.09 & 0.05 & 0.06 & 0.06 & 0.03 & 0.05 & 0.05 \\
\hline Uyluk & 0.04 & 0.04 & 0.08 & 0.04 & 0.02 & 0.03 & 0.08 & 0.04 & 0.07 & 0.05 & 0.04 & 0.02 & 0.04 \\
\hline Alt Bacak & 0.05 & 0.05 & 0.09 & 0.06 & 0.04 & 0.03 & 0.06 & 0.06 & 0.08 & 0.06 & 0.05 & 0.05 & 0.03 \\
\hline
\end{tabular}




\section{Adım 4: Gönderici ve Alıcı Gruplarının Belirlenmesi}

Eşitlik (6)-(8) kullanılarak etken ve etkilenen kriter grupları belirlenir. Tablo 6'da gösterildiği gibi boyun, omuzlar, sırt, bel ve diz kriteleri için $\mathrm{R}_{\mathrm{i}}-\mathrm{C}_{\mathrm{i}}$ değerleri pozitif değer aldıklarından dolayı diğer kriterler üzerinde daha yüksek etkiye sahiptirler ve gönderici grubundadırlar. Diğer kriterler ise negative $R_{i}-C_{i}$ değerine sahip olduklarından diğer kriterlerden etkilenirler ve bu kriterler alıcı grubundadırlar. $\mathrm{R}_{\mathrm{i}}+\mathrm{C}_{\mathrm{i}}$ değerleri yüksek olan sırt, bel ve diz kriterleri diğer kriterlerle daha fazla ilişkilidir.

\section{Adım 5: Kriter A ğırlıklarının Belirlenmesi}

Tablo 6' da verilen $\mathrm{R}_{\mathrm{i}}-\mathrm{C}_{\mathrm{i}}$ ve $\mathrm{R}_{\mathrm{i}}+\mathrm{C}_{\mathrm{i}}$ değerleri Eşitlik (9)-(10) kullanılarak Tablo 7'de gösterilen kriter ağırlıkları belirlenmiştir. Sonuç olarak Tablo 7'de fiziksel iş yükü faktörlerinin öncelikleri belirlenmiştir. Tablo 7'e bakıldığında UBT'lerde iş yükünü etkileyen en önemli ilk dört faktör bel, sirt, dizler ve omuzlar olduğu görülmektedir.

Tablo 6. Etken ve Etkilenen Grubun Belirlenmesi

\begin{tabular}{|c|c|c|c|c|}
\hline $\begin{array}{c}\text { Kriterler } \\
\text { (Faktörler) }\end{array}$ & $\mathbf{R i}$ & $\mathbf{C i}$ & $\mathbf{R i}+\mathbf{C i}$ & Ri- Ci \\
\hline Boyun & 1.08 & 0.93 & 2.00 & 0.15 \\
\hline Omuzlar & 1.17 & 0.90 & 2.07 & 0.27 \\
\hline Dirsekler & 0.53 & 1.30 & 1.83 & -0.77 \\
\hline El Bilekleri & 0.76 & 1.07 & 1.83 & -0.32 \\
\hline Sirt & 1.86 & 0.56 & 2.42 & 1.29 \\
\hline Bel & 1.88 & 0.55 & 2.43 & 1.33 \\
\hline Kalça & 0.77 & 1.24 & 2.01 & -0.48 \\
\hline Dizler & 1.11 & 1.00 & 2.11 & 0.11 \\
\hline $\begin{array}{c}\text { Ayak } \\
\text { Bilekleri }\end{array}$ & 0.69 & 1.15 & 1.84 & -0.46 \\
\hline Üst Kol & 0.76 & 1.05 & 1.81 & -0.29 \\
\hline Ön Kol & 0.69 & 0.96 & 1.65 & -0.26 \\
\hline Uyluk & 0.60 & 0.94 & 1.54 & -0.34 \\
\hline Alt Bacak & 0.70 & 0.95 & 1.65 & -0.25 \\
\hline
\end{tabular}

Tablo 7. Fiziksel iş yükü kriterlerinin ağırlıkları

\begin{tabular}{|l|c|}
\hline $\begin{array}{c}\text { İş Yükü } \\
\text { Kriterleri } \\
\text { (Faktörleri) }\end{array}$ & $\begin{array}{c}\text { Öncelik } \\
\text { Ăğırlıklandırılması }\end{array}$ \\
\hline BEL & 0,11 \\
\hline SIRT & 0,10 \\
\hline DİZLER & 0,08 \\
\hline OMUZLAR & 0,08 \\
\hline KALÇA & 0,08 \\
\hline BOYUN & 0,08 \\
\hline DİRSEKLER & 0,08 \\
\hline AYAK BİLEKLERİ & 0,07 \\
\hline EL BİLEKLERİ & 0,07 \\
\hline
\end{tabular}

\begin{tabular}{|l|l|}
\hline ÜST KOL & 0,07 \\
\hline ALT BACAK & 0,06 \\
\hline ÖN KOL & 0,06 \\
\hline UYLUK & 0,06 \\
\hline
\end{tabular}

\section{SonUÇLAR}

Havacılık sektöründe gerçekleştirilen görevlerin ve işlerin çeşitliliği, ergonomik risklerin ölçülmesini ve etkili azaltma stratejilerinin uygulanmasını zorlaştırmaktadır. $\mathrm{Bu}$ çalışmada UBT'lerin yaptıkları işlerde hangi fiziksel işyükü faktörlerinin daha büyük önem derecesine sahip olduğunu belirlemek için hat bakım konusunda uzman karar vericilerin görüşleri alınarak DEMATEL yöntemi kullanılmıştır.

UBT'lerde fiziksel iş yükünden dolayı kas iskelet sistemindeki rahatsızlıklar üzerine yapılan diğer çalışmalara benzer şekilde [19]; [20]; [22]; [23]; [24]; [25], bu çalışmada bel ve sirt bölgesinin en çok zorlanan bölgeler olduğu bulunmuştur. UBT'lerin kas-iskelet sistemi, teknisyenin farklı fiziksel yapısı ve fiziksel yeteneklerini aşan ağır parçaları kaldırılması da yaralanmalara yol açabilir. Bir uçağı kaldırmak için vinç gibi yardımcıların kullanılması, insanoğlunun fiziksel sınırlarını aşan görevleri yerine getirmeyi kolaylaştırabilir. Modern uçakların çoğu, uçak ekipmanına kolay erişim sağlamak, nesneleri gevşetmek veya sıkıştırmak için gerekli gücü uygulamak, vb. için bakım kolaylığı sağlayacak şekilde tasarlanmıştır. Ancak, bu çözümler UBT'ler için olası yaralanmaları önlemek için tamamen yeterli olmayabilir [26]. Bu nedenle bu çalışmada hat bakımda çalışan teknisyenler için özellikle en önemli fiziksel iş yükü faktörünün "bel ve sırt bölgesi" olarak ortaya çıkmasını açıklayabilir.

UBT’ler üzerinde fiziksel iş yükü faktörlerinin zararlı etkilerinin azaltılması için iş başı eğitimlerinde egzersiz ve ergonomi prensipleri hakkında bilgi verilmelidir. Maruz kalınan iş yüklerinin ergonomik açıdan en fazla ne kadar olması gerektiği konusunda çalışmalar artırılabilir. Çalışanlara aynı şekilde uygun takım ve ekipmanların kullanımı konusunda bilgilendirmeler yapılıp organizsayon bünyesinde temin edilebilir.

\section{Teşekkür}

Uzman ekibine desteklerinden dolayı çok teşekkür ederiz.

\section{Kaynakça}

[1] Bureau of LaborStatistics, 2016. ScheduledAirTransportation - OES Industry-Specific

[2] SHGM Faaliyet Raporu (2019) http://web.shgm.gov.tr/documents/sivilhavacilik/files/pdf/k urumsal/faaliyet/2019.pdf.

[3] Fontela, E. ve Gabus, A. (1974). DEMATEL, innovative methods. Report no. 2 structural analysis of the world problematique, Battelle Geneva Research Institute, Geneva, Switzerland, 67-69.

[4] Li, C., \& Tzeng, G. (2009). Identification of a threshold value for the DEMATEL method using the maximum mean de-entropy algorithm to find critical services provided by a 
semiconductor intellectual property mall. Expert Syst. Appl., 36, 9891-9898.

[5] C. W. Hsu, T. C. Kuo, S. H. Chen, and A. H. Hu. (2013). Using DEMATEL todevelop a carbonmanagement model of supplierselection in greensupplychainmanagement, Journal of CleanerProduction, vol. 56, pp. 164-172.

[6] Tseng, M. L., \& Lin, Y. H. (2009). Application of fuzzy DEMATEL to develop a cause and effect model of municipal solid waste management in Metro Manila. Environmental monitoring and assessment, 158(14), 519-533. https://doi.org/10.1007/s10661-008-0601-2

[7] Hu, H., Lee, Y., Yen, T., \& Tsai, C. (2009). Using BPNN and DEMATEL to modify importance-performance analysis model - A study of the computer industry. Expert Syst. Appl., 36, 9969-9979.

[8] Shieh, J., Wu, H.H., Huang, K.K. (2010), A DEMATEL Method in Identifying Key Success Factors of Hospital Service Quality, Knowledge-Based Systems, Volume 23, Issue 3, April 2010, 277-282

[9] Baykasoglu, A., Kaplanoglu, V., Durmusoglu, Z. D. U., \& Sahin, C. (2013). Integrating fuzzy DEMATEL and fuzzy hierarchical TOPSIS methods for truck selection. Expert Systems with Applications, 40(3), 899-907. https://doi.org/10.1016/j.eswa.2012.05.046

[10] Akay, D., Kurt, M. \& Dağdeviren, M. (2013). Çalişma Duruşlarinin Ergonomik Analizi. Gazi Üniversitesi Mühendislik Mimarlık Fakültesi Dergisi, 18 (3), Retrieved from https://dergipark.org.tr/tr/pub/gazimmfd/issue/6657/88995

[11] Crawford, J. O. (2007). The Nordic Musculoskeletal Questionnaire. Occupational Medicine-Oxford, 57(4), 300 301. https://doi.org/10.1093/occmed/kqm036

[12] Güneş, Ü, Ceylan, B. (2016). Akademisyen Hemşirelerin Bilgisayarli Çalişma Ortamindaki Ergonomik Koşullarinin Ve Buna Bağli Ortaya Çikan Kas-İskelet Sistemi Rahatsizliklarinin İncelenmesi. Ege Üniversitesi Hemşirelik Fakültesi Dergisi, 32 (2), 61-74. Retrieved from https://dergipark.org.tr/tr/pub/egehemsire/issue/49330/6301 $\underline{05}$

[13] Büyüközkan, G., \& Çifçi, G. (2012). A novel hybrid MCDM approach based on fuzzy DEMATEL, fuzzy ANP and fuzzy TOPSIS to evaluate green suppliers. Expert Systems with Applications, 39(3), 3000-3011. https://doi.org/10.1016/j.eswa.2011.08.162

[14] Lin, R. J. (2013). Using fuzzy DEMATEL to evaluate the green supply chain management practices. Journal of Cleaner Production, 40, 32-39.

[15] Rajesh, R., \& Ravi, V. (2015). Modeling enablers of supply chain risk mitigation in electronic supply chains: A GreyDEMATEL approach. Comput. Ind. Eng., 87, 126-139.

[16] Tsai, W., \& Chou, W. (2009). Selecting management systems for sustainable development in SMEs: A novel hybrid model based on DEMATEL, ANP, and ZOGP. Expert Syst. Appl., 36, 1444-1458.

[17] Aksakal, E.\& Dağdeviren.M. (2021). ANP ve DEMATEL yöntemleri ile personel seçimi problemine bütünleşik bir yaklaşım. Gazi Üniversitesi Mühendislik Mimarlık Fakültesi Dergisi, 25(4), 905-913.

[18] Bureau of LaborStatistics, 2015.NonfatalOccupationalInjuriesandIllnessesRequiring

[19] Chae, D.H. and Kim, J. H. (2005). Risk factors for musculoskeletal symptoms in aviation maintenance technicians. Korean Journal of Occupational Environment Medicine. 17(3):173-185.

[20] Zungu, L.I., Nigatu, E.S., (2015). A Comparative Study of the Prevalence and Risk Factors of Lower Back Pain among Aircraft Technicians in Ethiopian Airlines. In: Occupational Health Southern Africa. Vol. 21. SASOM (The South African Society of Occupational Medicine), https://journals.co.za/doi/10.10520/EJC169017

[21] Irwin, E., \& Streilein, K. (2015). Use of Field-based Motion Capture to Augment Observational data in ergonomic Assessment of Aircraft Maintenance. Procedia

[22] Rodriguez, H. A. F., \& Ortiz Mayorga, V. A. (n.d.) (2016). Characterization of low back pain in pilots and maintenance technicians on a commercial airline. Aerospace Medicine and Human Performance, 87(9), 795-799. https://doi.org/10.3357/AMHP.4384.2016

[23] Nogueira, H. C., Diniz, A. C., Barbieri, D. F., Padula, R. S., Carregaro, R. L., \& de Oliveira, A. B. (2012). Musculoskeletal disorders and psychosocial risk factors among workers of the aircraft maintenance industry. Work (Reading, Mass.), 41 Suppl 1, 4801-4807. https://doi.org/10.3233/WOR-2012-0767-4801

[24] Asadi, H., Yu, D., \& Mott, J.H. (2019). Risk factors for musculoskeletal injuries in airline maintenance, repair \& overhaul. International Journal of Industrial Ergonomics, 70, 107-115.

[25] Yazgan, E, Ozkan, N.F ve Ulutaş, B.H. (2021). A Questionnaire-based musculoskeletal disorder Assessment for aircraft maintenance technicians. Aircraft Engineering and Aerospace Technology, DOI 10.1108/AEAT-03-20210076.

[26] CAA, Civil Aviation Authority (2002), CAP 715: an introduction to aircraft maintenance engineering human factors for JAR 66., https://publicapps.caa.co.uk/docs/ 33/CAP715.PDF (accessed 02 Ekim 2021). 